\title{
PERSEPSI IBU TERHADAP PERSALINAN DENGAN DUKUN BAYI DI DESA TUNDAGAN KECAMATAN WATUKUMPUL KABUPATEN PEMALANG
}

\author{
Rose Nurhudhariani ${ }^{1}$, Minkhatul Maula ${ }^{2}$ \\ ${ }^{1,2}$ Prodi D IV Bidan Pendidik, STIKES Karya Husada Semarang \\ Email : rose.djogja@gmail.com
}

\begin{abstract}
ABSTRAK
Latar Belakang: AKI dan AKB merupakan salah satu aspek yang sangat penting dalam mendeskripsikan tingkat pembangunan manusia di suatu negara dari sisi kesehatan masyarakatnya. Angka Kematian Ibu di Jawa Tengah tahun 2012 sebesar 116,34 per 100.000 kelahiran hidup, di Puskesmas Watukumpul Persalinan dengan nakes dari bulan januari sampai agustus 2015 adalah 60 ibu bersalin sedangkan persalinan dengan non nakes sebanyak 34 ibu bersalin. Tujuan: Tujuan dari penelitian ini adalah untuk mengeksplorasi persepsi ibu bersalin, faktor-faktor yang mempengaruhi dan dukungan keluarga ibu bersalin dengan dukun bayi. Metode: Penelitian ini menggunakan metode kualitatif dengan pendekatan fenomologi. Teknik pengumpulan data dengan wawancara mendalam. Jumlah partisipan 3 ibu bersalin dengan dukun bayi dan triangulasi suami partisipan, tokoh agama, bidan desa dan dukun bayi Desa Tundagan. Hasil: Hasil wawancara mendalam pada partisipan sudah mengetahui tentang persalinan dengan dukun bayi. Pertolongan persalinan dengan dukun bayi yang masih tradisional yaitu jika bayi sudah lahir cara memotong tali pusar dengan silet dan melahirkan placenta dengan cara di perut ditekan supaya placenta bisa keluar. Semua ibu bersalin setuju persalinan dengan dukun bayi dan semua keluarga mendukung ibu bersalin dengan dukun bayi.Pihak puskesmas lebih sering melakukan penyuluhan bagaimana pentingnya bersalin dengan tenaga kesehatan di Desa Tundagan.
\end{abstract}

Kata Kunci : Persepsi; Ibu bersalin; Dukun bayi.

Daftar Pustaka : 38 (2002-2013)

\section{MOTHER PERCEPTIONS OF CONFINEMENT by TRADITIONAL HEALTH PRACTITIONAR IN TUNDAGAN VILLAGE}

\begin{abstract}
Background: AKI and AKB constitute one of aspect that very important to described level of human development in a country from social sanitary side. The number of mother death in Center of Java on 2012 in the amount of 116.34 per 100.000 birth of life, in Watukumpul health center. The confinement by midwife since January until August 2015 amount of 60 maternity. Meanwhile, the confinement without a midwife amount of 34 maternity. Purpose: The purpose of this research is to explore perception of mothers about the factors that influencing and support mother maternity by midwife. Method: This research was using qualitative method with phenomonology approach. Data accumulation technique with visceral interview, 3 mothers maternity by midwife and triangulation participant husband, religion personage, midwife in Tundagan village. Result: Result of visceral interview into participant had known already about confinement with a midwife. Aid of confinement by a midwife that still traditional namely if baby was born, the way to cutting an umbilical cord is using razor blade and give birth of placenta by belly pressed, so the placenta can be out. All of mother maternity agree with confinement by midwife, and all of family were support it. The health center more often do counseling how important maternity with health workers or midwife in Tundagan village.
\end{abstract}

Key word: Perception; Mother Maternity; Midwife

Bibliography: 38 (2002-2013) 


\section{Pendahuluan}

Angka Kematian Ibu (Infant Mortality Rate) dan Angka Kematian Bayi merupakan salah satu aspek yang sangat penting dalam mendeskripsikan tingkat pembangunan manusia di suatu negara dari sisi kesehatan masyarakatnya. Data Survei Demografi Kesehatan Indonesia (SDKI) mengumumkan hasil capaian AKI di Indonesia pada tahun 2012 meningkat menjadi 359 per 100.000 kelahiran hidup atau mengembalikan pada kondisi tahun 1997. Berarti kesehatan ibu justru mengalami kemunduran selama 15 tahun. Tahun 2007, AKI di Indonesia sebenarnya telah mencapai 228 per 100.000 kelahiran hidup, serta AKB di Indonesia tahun 2007 adalah 34 per 1000 kelahiran hidup (SDKI, 2012).Data kesehatan Provinsi Jawa Tengah, Angka Kematian Ibu (AKI) di Jawa Tengah tahun 2012 sebesar 116,34 per 100.000 kelahiran hidup dan Angka Kematian Bayi (AKB) tahun 2012 sebesar 10,75 per 1000 kelahiran hidup (Dinkes Jateng, 2012). Wilayah Kabupaten Pemalang tahun 2013 menyebutkan AKI sebesar 111,06 per 100.000 kelahiran hidup dan AKB sebesar 8,9 per 1000 kelahiran hidup (Dinkes Kabupaten Pemalang, 2013).Persalinan yang aman memasti kan bahwa semua penolong persalinan mempunyai pengetahuan,ketrampilan, dan alat untuk memberikan pertolongan yang aman dan bersih, serta memberikan pelayanan nifas kepada ibu dan bayi (Sarwono, 2006).

Tenaga yang dapat memberikan pertolongan persalinan dapat dibedakan menjadi 2, yaitu tenaga profesional dan dukun bayi (Dinkes Jateng, 2007). Daerah pedesaan, kebanyakan ibu hamil masih mempercayai dukun beranak untuk menolong persalinan yang biasanya dilakukan di rumah. Beberapa penelitian yang pernah dilakukan mengungkapkan bahwa masih terdapat praktik-praktik persalinan oleh dukun yang dapat membahayakan ibu. Penelitian menunjukan beberapa tindakan praktik membawa risiko infeksi seperti "ngolesi" (membasahi vagina dengan minyak kelapa untuk memperlancar persalinan), "kodok" (memasukan tangan ke dalam vagina dan uterus untuk mengeluarkan placenta) atau " nyanda" (setelah persalinan ibu duduk dengan posisi bersandar kaki diluruskan kedepan selama ber jam-jam) yang dapat menyebabkan perdarahan dan pembengkakan (Iskandar 1996 dalam Alexandra, 2012).

Daerah pedesaan, keputusan terhadap perawatan medis yang akan dipilih harus dengan persetujuan kerabat yang lebih tua atau keputusan berada di tangan suami yang sering kali menjadi panik melihat keadaan krisis yang terjadi. Kepanikan dan ketidaktahuan akan gejalagejala tertentu saat persalinan dapat menghambat tindakan yang seharusnya dilakukan dengan cepat (Alexandra, 2012). 
Studi pendahuluan di Puskesmas Watukumpul Persalinan dengan nakes dari bulan januari sampai juni 2015 adalah 45 ibu bersalin sedangkan persalinan dengan non nakes sebanyak 26 ibu bersalin. Data tersebut didapatkan oleh peneliti dari Bidan koordinator Puskesmass Watukumpul. Faktor-faktor yang mempengaruhi yaitu faktor lingkungan sosial yaitu kepercayaan masyarakat Desa Tundagan mengenai penolong persalinan lebih memilih dukun dibanding bidan sehingga mereka, mengarahkan keluarga mereka untuk bersalin dengan dukun, faktor jarak tempat tinggal yang terlalu jauh dari sarana kesehatan membuat masyarakat Desa Tundagan enggan untuk bersalin dengan tenaga bidan, dan faktor tingkat pendidikan yaitu rata-rata pendidikan masyarakat Tundagan masih rendah sehingga pemanfaatan terhadap pelayanan kesehatan masih rendah.Berdasarkan uraian latar belakang di atas, saya ingin meneliti dan mengambil judul tentang "Persepsi Ibu terhadap persalinan dengan sukun bayi di Desa Tundagan Kecamatan Watukumpul Kabupaten Pemalang”

\section{Tinjauan Teoritis}

Persalinan dan kelahiran merupakan kejadian fisiologis yang normal dalam kehidupan. Kelahiran serorang bayi juga merupakan peristiwa sosial bagi ibu dan keluarga. Peranan ibu adalah melahirkan bayinya, sedangkan peranan keluarga adalah memberikan bantuan dan dukungan pada ibu ketika terjadi proses persalinan. Dalam hal ini peran petugas kesehatan sangat penting dalam memberikan bantuan dan dukungan pada ibu agar seluruh rankaian proses persalinan berlangsung dengan aman baik bagi ibu maupun bagi bayi yan dilahirkan (Sumarah dkk, 2008).

Fokus Asuhan Persalinan Normal adalah persalinan bersih dan aman serta mencegah terjadinya komplikasi. Hal ini merupakan pergeseran paradigma dari menunggu terjadinya dan menangani komplikasi, menjadi pencegahan komplikasi. Persalinan bersih dan aman serta pencegahan komplikasi selama pascapersalinan terbukti mampu mengurangi kesakitan atau kematian ibu dan bayi baru lahir (JNPK-KR, 2008).Penolong persalinan dengan nakes atau Bidan, Alexandra (2012), mengatakan Bidan adalah seseorang yang telah menyelesaikan pendidikan kebidanan yang diakui dan mendapat lisensi untuk melaksanakan praktik kebidanan. Selain itu bidan dikenal juga sebagai petugas kesehatan khusus yang melayani praktik asuhan kebidanan baik yang merupakan bidan negeri maupun bidan swasta yang menjalankan praktik asuhan kebidanan, sehingga kompetensi jelas dan tidak overlap dengan petugas kesehatan lainnya. Penolong persalinan non nakes atau dukun menurut Kusnanda 
Adimiharja, dukun bayi adalah seorang wanita atau pria yang menolong persalinan. Kemampuan ini diperoleh secara turun temurun dari ibu kepada anak atau dari keluarga dekat lainnya. Cara mendapat keterampilan ini adalah melalui magang dari pengalaman sendiri atau saat membantu melahirkan. Suparlan mengatakan dukun bayi adalah mereka yang memberi pertolongan pada waktu kelahiran atau dalam hal-hal yang berhubungan dengan pertolongan persalinan (Kusumandari, 2010).

\section{Metode Penelitian}

Penelitian ini termasuk penelitian kualitatif, yaitu dengan pendekatan fenomologis yang mengembangkan konsep-konsep pemahaman lebih dalam atas fenomena sosial perilaku dalam seting alamiah(saryono, 2013).Partisipan dalam penelitian ini adalah ibu bersalin dengan dukun bayi di Desa Tundagan Kecamatan watukumpul Kabupaten Pemalang. Tiangulasi pada bidan desa, tokoh agama, suami ibu bersalin dan dukun bayi.

\section{Hasil Penelitian Dan Pembahasan}

1. Mengeksplorasi persepsi ibu bersalin dengan dukun bayi

Berdasarkan hasil penelitian didapatkan bahwa semua partisipan mengetahui tentang persalinan dengan dukun bayi. Menurut 2 dari 3 partisipan yaitu partisipan 1 dan 3 mengatakan bahwa persalinan dengan dukun bayi adalah persalinan yang ditolong sama dukun, sedangkan partisipan 2 mengatakan bahwa persalinan dengan dukun adalah persalinan yang ditunggui dukun bayi.

Triangulasi suami 2 menyatakan bahwa persalinan dengan dukun bayi. Pengetahuan tentang persalinan dengan dukun bayi rata-rata ibu sudah mengetahuinya sejak lama, dibuktikan dengan jawaban dari partisipan 2 dan 3 mengatakan bahwa mereka sudah mengetahui tentang persalinan dengan dukun bayi sejak dulu. Sedangkan partisipan 1 mengetahui tentang persalinan dengan dukun bayi sejak hamil. Hal ini diperkuat dengan pernyataan triangulasi suami 2 yang mengatakan bahwa sudah mengetahui dari dulu dan dia sendiri lahir dengan dukun bayi.

Informasi mengenai persalinan dengan dukun bayi sebagian besar didapatkan dari keluarga dan tetangga. partisipan 1 dan 3 mengatakan bahwa mendapatkan informasi mengenai persalinan dengan dukun bayi dari keluarga, tetangga dan mertua, sedangkan partisipan 2 mengatakan bahwa mendapatkan informasi mengenai persalinan dengan dukun bayi dari nenek dan ibunya. Menurut triangulasi suami informasi mengenai persalinan dengan dukun 
bayi memang di dapat dari keluarga, saudara dan tetangga karena mayoritas di Desa Tundagan ibu hamil bersalin dengan dukun bayi dan sudah umum bersalin dengan dukun bayi .Dukun bayi adalah orang yang dianggap terampil dan dipercaya oleh masyarakat untuk menolong persalinan dan perawatan ibu dan anak sesuai kebutuhan masyarakat (Rini Nurdianti, 2011). Masyarakat sudah mengenal dukun bayi atau dukun beranak sebagai tenaga pertolongan persalinan yang diwariskan secara turun temurun. Dukun bayi yaitu mereka yang memberi pertolongan pada waktu kelahiran atau dalam hal-hal yang berhubungan dengan pertolongan kelahiran, seperti memandikan bayi.Pada kelahiran anak dukun bayi yang biasanya adalah seorang wanita tua yang sudah berpengalaman, membantu melahirkan (Parlin, 201 1).

Upaya meningkatkan derajat kesehatan terutama ditujukan kepada golongan yang rawan terhadap penyakit, yaitu bayi, balita dan ibu hamil. Indikator keberhasilan pembangunan kesehatan pada sektor kesehatan ibu dan anak dapat dilihat dari angka kematian ibu (AKI) dan angka kematian bayi (AKB).Oleh karena itu, Program promosi kesehatan mempunyai peran yang sangat penting dalam proses pemberdayaan masyarakat, yaitu proses pembelajaran dari, oleh, untuk dan bersama masyarakat sesuai dengan sosial budaya setempat, agar masyarakat dapat menolong dirinya dalam bidang kesehatan. Penolong persalinan merupakan salah satu indikator perilaku hidup bersih dan sehat yang dipengaruhi oleh kondisi wilayah dan budaya (Depkes, 2006).

2. Mengeksplorasi faktor-faktor yang mempengaruhi ibu bersalin dengan dukun bayi

Semua partisipan setuju jika persalinan dilakukan oleh dukun bayi, karena di Desa Tundagan sudah terbiasa bersalin dengan dukun bayi. Menurut 2 dari 3 partisipan yaitu partisipan 2 dan 3 mengatakan bahwa di Desa Tundagan masih banyak persalinan yang ditolong oleh dukun dan di Desa Tundagan persalinan oleh dukun sudah umum sekali, partisipan 2 bahkan menambahkan bahwa persalinan yang ditolong bidan adalah persalinan yang bermasalah apabila tidak ada masalah bisa dipastikan bersalin dengan dukun bayi. Triangulasi 2 juga menguatkan pernyataan partisipan 2 dan 3, hal ini dibuktikan dengan pernyataan triangulasi 2 yaitu umumnya banyak yang bersalin dengan dukun bayi karena ibu yang bersalin dengan bidan disebabkan persalinannya bermasalah. Sedangkan partisipan yang lain yaitu partisipan 1 mengatakan di Desa Tundagan banyak yang bersalin dengan dukun bayi. Triangulasi 3 menyatakan bahwa di Desa Tundagan memang masih banyak yang bersalin dengan dukun bayi sekitar 50\%. Menurut 2 dari 3 partisipan yaitu partisipan 1 dan 3 mengatakan bahwa jarak rumah mereka dengan rumah dukun bayi lebih dekat dibandingkan dengan rumah bidan Desa Tundagan cukup dengan berjalan kaki. Jawaban tersebut diperkuat 
dengan pernyataan suami bahwa salah satu alasan bersalin dengan dukun bayi karena jaraknya dekat.. Sedangkan partisipan yang lain yaitu partisipan 2 mengat akan bahwa jarak rumah ibu bersalin dengan dukun bayi cukup jauh. Lama perjalanan dari rumah ibu bersalin ketempat dukun bayi rata-rata mengatakan hanya butuh waktu sekitar 15 menit. Terbukti bahwa menurut 2 dari 3 partisipan yaitu partisipan 1 dan 3 mengatakan bahwa lama perjalanan dari rumah ibu bersalin ketempat dukun bayi hanya membutuhkan waktu sekitar 15 menit. Triangulasi 2 pun menyebutkan bahwa bagi ibu hamil yang jarak rumahnya dekat dengan rumah dukun bayi hanya membutuhkan waktu sekitar seperempat jam saja dan sekitar 30 menit bagi ibu hamil yang rumahnya jauh dengan dukun bayi. Sedangkan satu partisipan lain yaitu partisipan 2 mengatakan bahwa lama perjalanan dari rumah ibu bersalin ke rumah dukun bayi lumayan lama sekitar 30 menit karena jarak rumah cukup jauh dengan rumah dukun bayi.

Keluarga ibu banyak yang bersalin dengan dukun bayi bahkan hampir semua ibu bersalin lebih memilih bersalin dengan dukun bayi. Menurut 2 dari 3 partisipan yaitu partisipan 2 dan 3 mengatakan bahwa tidak hanya dari keluarga mereka yang bersalin dengan dukun bayi tetapi tetangga-tetangga mereka juga banyak yang bersalin dengan dukun bayi. Sedangkan partisipan yang lain, yaitu partisipan 1 hanya mengatakan bahwa rata-rata dari keluarga semua bersalin dengan dukun bayi. Hal ini sama dengan pernyataan yang diungkapkan triangulasi suami bahwa tetangga juga bersalin dengan dukun bayi dan orang tua juga bersalin dengan dukun bayi. Alasan ibu bersalin dengan dukun bayi kebanyakan karena masalah biaya yaitu lebih murah dibanding dengan bidan. Menurut 2 dari 3 partisipan, yaitu partisipan 2 dan 3 mengatakan bahwa mereka memilih bersalin dengan dukun bayi karena lebih murah,. Triangulasi pernyataan partisipan 2 dan 3 sesuai dengan pernyataan triangulasi suami dengan triangulasi 2 yang menyatakan bahwa bersalin dengan dukun bayi lebih murah apabila ada yang kurang, komunikasi dengan dukun bayi lebih mudah.. Sedangkan partisipan lain yaitu partisipan 1 mengatakan bahwa ibu bersalin lebih memilih bersalin dengan dukun bayi karena memang sudah percaya dengan dukun bayi, menurutnya dukun bayi sudah pasti bisa mengurus ibu-ibu yang mau bersalin, dan jika bersalin dengan dukun bayi pasti diberi jamu dan diurut. Triangulasi 2 dan triangulasi suami juga menyatakan hal yang sama yaitu memilih bersalin dengan dukun bayi karena memang sudah percaya dengan dukun bayi.Perbedaan persalinan dukun bayi dengan tenaga kesehatan menurut partisipan 1 dan 3 adalah jika bersalin dengan bidan diberi obat dan disuntik sedangkan dengan dukun diberi jamu. Partisipan 1 juga menambahkan jika bersalin dengan dukun bayi diberi jamu raccikan dan diurut ,bayinya juga diurus sampai 40 hari, dan cara menolong persalinannya juga beda 
dengan bidan kalau dengan dukun perutnya dipegang dan disuruh mengejan, sedangkan bidan harus menunggu pembukaan lengkap. Partisipan 2 menyatakan perbedaanya adalah bersalin dengan bidan lebih mahal dan bersalin dengan dukun lebih murah dengan tujuan sama yaitu untuk mengeluarkan bayi. Triangulasi 2 juga menyebutkan bahwa bersalin dengan dukun bayi lebih murah, lebih dekat dibanding dengan bidan lebih mahal dan lebih jauh. Triangulassi dukun menyatakan bahwa jika bersalin dengan dukun memang diberi jamu racikan dan diurut setelah bersalin cara menolongnya juga berbeda karena cara menolong persalinan jika dengan dukun masih menggunakan cara tradisional,Keuntungan dan kerugian bersalin dengan dukun bayi menurut 2 dari 3 partisipan karena biaya murah bahkan jika hanya dibayar dengan satu ekor ayam dan uang seikhlasnya dukun bayi tidak keberatan. Berbeda dengan 2 partisipan yang diatas partisipan yang lain yaitu partisipan 1 mengatakan keuntungan bersalin dengan dukun bayi adalah karena jarak rumah yang dekat sehingga saat memanggil tidak terlalu jauh dan biaya bisa seikhlasnya seandainya belum punya uang pun bisa dihutang dulu. Triangulasi suami 1, 3 dan triangulasi 2 menyatakan bahwa bersalin dengan dukun karena jarak rumah yang dekat sehingga tidak terlalu jauh untuk memanggil dukun dan biaya yang relative murah dan apabila belum ada uang bisa dihutang dulu. Sedangkan kerugian bersalin dengan dukun bayi menurut 2 dari 3 partisipan yaitu partisipan 1 dan 2 menurut mereka tidak ada kerugiannya, akan tetapi menurut partisipan 3 kerugian dari bersalin dengan dukun bayi adalah sering was-was karena faktor kebersihan pada dukun bayi yang terkadang tidak bersih. Hal ini sesuai dengan pernyataan dari triangulasi 2 yang menyakatan bahwa ada rasa takut karena peralatan dukun bayi tidak komplit dan tidak lengkap.

Dukun bayi menyatakan bahwa kalau bersalin perut ibu dipegang, jika keluar lendir , kenceng terus menerus, anusnya mengembang ibu diminta mengejan. Ibu mendapatkan jamu dari bahan-bahan alami, seperti lempuyang, kamijara, temulawak, temu ireng. Jika perineum sobek tidak dijahit, menurut dukun bayi luka tersebut akan sembuh sendiri. Tali pusat dipotong menggunakan silet dan diberi obat merah. Melahirkan placenta dengan cara perut ibu diteka. Setelah semua lahir ibu di pijat semua badan dan perut menggunakan minyak goring kemudian minum jamu campur gula sama asem.

Kehamilan merupakan proses reproduksi yang normal, tetapi perlu perawatan diri yang khusus agar ibu dalam keadaan sehat. Karena itu kehamilan yang normal pun mempunyai risiko kehamilan dan persalinan, namun tidak secara langsung meningkatkan risiko kematian ibu. Keadaan-keadaan tersebut dinamakan faktor risiko. Semakin banyak ditemukan faktor risiko pada seorang ibu hamil, maka semakin tinggi risiko kehamilannya 
(Azwar, 2011).Pada pertolongan persalinan di rumah, perlu diwaspadai adanya risiko infeksi dikarenakan paparan lingkungan yang tidak bersih, alas persalinan yang tidak bersih, serta alat dan tangan penolong yang tidak bersih karena mobilisasi dari pusat pelayanan kesehatan ke rumah ibu (Prastyawati, 2012).Seperti diketahui, dukun bayi adalah merupakan sosok yang sangat dipercayai di kalangan masyarakat. Mereka memberikan pelayanan khususnya bagi ibu hamil sampai dengan nifas secara sabar. Apabila pelayanan selesai mereka lakukan, sangat diakui oleh masyarakat bahwa mereka memiliki tarif pelayanan yang jauh lebih murah dibandingkan dengan bidan. Umumnya masyarakat merasa nyaman dan tenang bila persalinannya ditolong oleh dukun atau lebih dikenal dengan bidan kampung, akan tetapi ilmu kebidanan yang dimiliki dukun tersebut sangat terbatas karena didapatkan secara turun temurun (tidak berkembang) (Meilani dkk, 2009).

3. Mengeksplorasi dukungan keluarga ibu bersalin dengan dukun bayi

Dukungan keluarga rata-rata semua keluarga partisipan mendukung ibu bersalin dengan dukun bayi, menurut partisipan 1 dan 2 keluarga mereka mendukung ibu bersalin dengan dukun bayi. Sedangkan partisipan 3 menjelaskan lebih rinci bahwa keluarga, suami dan ibu kandung mendukung sekali ibu bersalin dengan dukun bayi.Lingkungan merupakan semua yang terlibat dalam interaksi individu pada waktu melaksanakan aktifitasnya, baik lingkungan fisik, psikososial, biologis maupun budaya. Lingkungan psikososial meliputi keluarga, kelompok, komunitas dan masyarakat. Ibu selalu terlibat dalam interaksi keluarga, kelompok, komunitas, dan masyarakat. Masyarakat merupakan kelompok paling penting dan kompleks yang telah dibentuk oleh manusia sebagai lingkungan sosial yang terdiri dari individu, keluarga dan komunitas yang mempunyai tujuan dan sistem nilai.Perempuan merupakan bagian dari anggota keluarga dari unit komunitas. Keluarga yang dalam fungsinya mempengaruhi dan dipengaruhi oleh lingkungan dimana dia berada. Keluarga dapat menunjang kebutuhan sehari-hari dan memberikan dukungan emosianal kepada ibu sepanjang siklus kehidupannya. Keadaan sosial ekonomi, pendidikan, kebudayaan dan lokasi tempat tinggal keluarga sangat menentukan derajat kesehatan reproduksi perempuan (Kusumandari, 2010).

\section{Kesimpulan}

1. Semua pengetahuan ibu bersalin tentang persalinan dengan dukun bayi yaitu persalinan yang ditolong dan ditunggui oleh dukun bayi. Ibu bersalin mengetahui tentang 
persalinan dengan dukun bayi sejak dulu. Rata-rata ibu bersalin mengetahui persalinan dengan dukun bayi yaitu dari turun temurun dari keluarga ibu bersalin.

2. Semua ibu hamil setuju jika persalinan ditolong oleh dukun bayi. Budaya di Desa Tundagan ibu yang akan melahirkan ditolong oleh dukun bayi. Jarak anatara rumah ibu bersalin dengan rumah dukun bayi lebih dekat dibandingkan dengan rumah bidan. Keluarga ibu bersalin rata-rata bersalin dengan dukun bayi. Semua ibu bersalin memilih bersalin dengan dukun bayi karena jarak rumah yang dekat dan biaya yang lebih murah. Perbedaan bersalin dengan dukun bayi dan tenaga kesehatan hanya berbeda pada obat dan metode yang diberikan. Dukun bayi memberikan jamu, perut diurut, jika keluar lender darah dan kenceng terus menerus, ibu diminta mengejan, dipijat selama 40 hari pasca melahirkan, jika perineum robek tidak dijahit. Keuntungan dan kerugian bersalin dengan dukun bayi rata-rata tidak mengetahui kerugian bersalin dengan dukun bayi. Persalinan dengan dukun menimbulkan rasa khawatir karena kurangnya kebersihan dan kelengkapan alat.

3. Semua keluarga ibu bersalin mendukung ibu untuk bersalin dengan dukun bayi.

\section{Saran}

1. Bagi Dinas Kesehatan

Diharapkan dapat lebih berkontribusi terhadap program persalinan dengan tenaga kesehatan dan lebih proaktif terhadap kejadian persalinan dengan dukun bayi yang ada di wilayah kerja Puskesmas Watukumpul.

2. Bagi Puskesmas

Diharapkan pihak puskesmas lebih sering melakukan kunjungan ibu hamil dan melakukan penyuluhan bagaimana pentingnya bersalin dengan tenaga kesehatan di Desa Tundagan.

3. Bagi Masyarakat Desa Tundagan

a. Diharapkan tokoh agama Desa Tundagan mau bekerja sama dengan Bidan agar persalinan bisa ditolong di fasilitas kesehatan.

b. Diharapkan masyarakat Desa Tundagan mengerti pentingnya bersalin dengan tenaga kesehatan, dan ibu bersalin primipara di Desa Tundagan untuk kehamilan selanjutnya diharapkan mau bersalin dengan tenaga kesehatan. 


\section{Daftar Referensi}

Alexandra, I. (2012). Sosiologi kebidanan, cetakan 1. Yogyakarta: Rona Pancaran Ilmu.

Arsita Eka Prasetyawati, 2012. Kesehatan Ibu dan Amak (KIA) dalam Millenium Development Goals Yogyakarta : Nuha Medika.

Azwar, (2011), Strategi Percepatan Penurunan Kematian Ibu Melalui PeningkatanKualitas Pelayanan, Advocasi Workshop Strategi dan Kegiatan yang Berhasil dalam Program Safe Motherhood.Depkes RI, Jakarta.

Depkes, RI. \& BPS (2006). Perilaku Hidup Bersih dan Sehat di Indonesia 2004. Jakarta

Dinas Kesehatan Jawa Tengah. (2007). Profil kesehatan profinsi Jawa Tengah tahun 2007.

Dinas Kesehatan Kabupaten Pemalang. (2013). Profil Kesehatan Kabupaten Pemalang tahun 2013.

JNPK-KR. (2008). Asuhan persainan normal. Jakarta: Lembaga Konsultan Peraturan Bisnis Indonesia ISBN

Kusumandari, W. (2010). Bidan sebuah pendekatan midwifery of knowledge. Yogyakarta: Nuha Medika

Moleong, J. Dr.Lexy. 2007. Metodologi penelitian kualitatif. Bandung : CV. Remadja Karya

Rini nurdianti,2011. Persalinan Oleh Dukun Bayi.http://www.diakses pada tanggal 17 November 2011

Sumarah, dkk. (2008). Perawatan ibu bersalin (Asuhan Kebidanan Pada Ibu Bersalin) . Yogyakarta: Fitramaya 